\title{
Reproductive ultrasonography: an important tool for the study of reproductive physiology in camelids
}

\section{J. Selva Andina Anim. Sci. 2021; 8(1):1-2.}

Ultrasonography has established itself as one of the main diagnostic imaging techniques used in veterinary practice. It allows obtaining information instantaneous and dynamic on a wide range of body systems and specifically in the dynamic evaluation of some organs. Several new applications are regularly described, such as ultrasonographic equipment with higher frequency (in $\mathrm{MHz}$ ) and the Doppler system, which allow and/or lead to new knowledge about anatomy and different physiological processes, specifically from the reproductive in domestic animals ${ }^{1}$.

Reproductive physiology in South American camelids is characterized by the presence of consecutive and overlaping follicular waves, in addition to having induced ovulation. Several authors divide the follicular wave in phases such as: recruitment, dominance, static and regression in general, which allows characterizing and demonstrating that females are receptive to the male during the duration of the follicular wave. However, there is still some knowledge to be studied and described, such as follicular selection and deviation on which the response to multiovulation protocols and subsequent survival of embryos; the more studies of oocyte viability from dominant follicles in different stages of the follicular wave (growth, static and regression) and its direct relationship with greater or lesser fertility in South American camelids; all these processes could be efficiently described with tools such as hormone dosage and Doppler ultrasonography ${ }^{2-4}$.

The Doppler technique is characterized by generating a greater amount of objective data on the study of reproductive processes such as, mainly: the follicular and luteal vascular area by means of "color Doppler" and "Doppler power" that allow characterizing the amount of blood fluid that reaches the organ and that translates into greater functionality of the same, technique widely used in bovines ${ }^{5}$; all these techniques have already begun to be used in South American camelids especially for the study of the formation of the corpus luteum that will allow knowing the vascularization process of this organ and its relation with an increase in fertility either by reproductive techniques such as mating as well as embryo transfer ${ }^{6}$. The generation of knowledge requires a lot of time, resources and advice in this sense, it seems prudent to thank the unconditional support and understanding of my family and the Reproduction Laboratory of the Faculty of Medicine Veterinary and Zootecnic of the National University of the Altiplano Puno with its representative Dr. Manuel Guido Perez Durand and all the research group he represents, for the opportunity to continue exploring this still unknown world of reproductive physiology in South American camelids and to inform them of our commitment in the generation of new knowledge that can serve in the development of this important species for our brothers producers of the Andes; in the same way to thank the international indexed 
Journal of the Selva Andina Animal Science, which despite the global health situation allows to disseminate and mainly share scientific knowledge through the manuscripts presented.

\section{Cited literature}

1. Perez Guerra UH, Quispe YM, Perez G, editores. Ultrasonografía reproductiva: US en bovinos, camélidos y ovinos. Chisináu: Editorial Académica Española; 2018.

2. Cavilla MV, Bianchi CP, Maistruarena C, Aba MA. Ultrasonographic and endocrine characterization of follicular waves in llamas with a special reference to the overlapping phenomenon during successive waves. Reprod Domest Anim 2013;48(6):923-30. DOI: https://doi.org/10.1111/rda.12187

3. Gallelli MF, Bianchi C, Zampini E, Aba M, Gambarotta M, Miragaya M. Plasma IGF1 and 17ßEstradiol concentrations during the follicular wave in llamas. Front Vet Sci 2020;7:555261. DOI: https://doi.org/10.3389/fvets.2020.555261

4. Perez U, Pari D, Gutierrez F, Málaga J, Luque N, Rojas R, et al. Comparación ultrasonográfica transvaginal y transrectal de la dinámica folicular en ondas sucesivas de llamas (Lama glama). Rev Investig Vet Perú 2021;32(1):e19504. DOI: http://doi.org/10.15381/rivep.v32i1.19504

5. Hassan M, Arshad U, Bilal M, Sattar A, Avais M, Bollwein H, et al. Luteal blood flow measured by Doppler ultrasonography during the first three weeks after artificial insemination in pregnant and nonpregnant Bos indicus dairy cows. J Reprod Dev 2019;65(1):29-36. DOI: https://doi.org/10.1262/jrd.2018-084

6. Gallelli MF, Bianchi C, Zampini E, Trasorras V, Gambarotta M, Miragaya M. Corpus luteum vascularization during the maternal recognition of pregnancy in llamas (Lama glama). Reprod Domest Anim 2020;55(1):74-80. DOI: https://doi.org/10.1111/rda.13588

Perez Guerra Uri Harold

National University of the Altiplano Puno Faculty of Veterinary Medicine and Zootechnics Animal Reproduction Laboratory Av. Panama No 710, Puno, Peru Tel: + 051-599430 E-mail: uperez@unap.edu.pe 